\title{
Predictive Factors Affecting the Clinical Course of Patients With Diverticulitis: Who Needs Hospital Management?
}

\author{
Taeyoung Yoo, Keun Ho Yang, Jungbin Kim, Inseok Park, Hyunjin Cho, Geumhee Gwak, Byung Noe Bae, \\ Ki Hwan Kim \\ Department of Surgery, Inje University Sanggye Paik Hospital, Inje University College of Medicine, Seoul, Korea
}

Purpose: The aim of this study is to determine the predictable factors that affect the clinical course, especially the hospital stay, the operation performed, and to determine factors that will be helpful in deciding whether in-hospital or outpatient treatment is appropriate.

Methods: We retrospectively collected medical data for patients who had been diagnosed with acute diverticulitis at Inje University Sanggye Paik Hospital between January and December 2016. In total, 117 patients were enrolled in this study. We examined clinical factors, including age, sex, body mass index, pain, body temperature, white blood cell count, C-reactive protein, nil per os (NPO) time, hospital duration, computed tomography (CT) findings, location of diverticulitis, operation performed, and presence of comorbidity (e.g., hypertension and diabetes mellitus).

Results: In the multivariate analysis, the statistically significant factor related with hospital duration was the presence of perforation on the CT scan $(\mathrm{P}<0.001)$. Longer NPO time was related with pain score $(>7)(\mathrm{P}=0.011)$. Operations were mainly performed in patients with left-sided colonic diverticulitis $(\mathrm{P}=0.012)$.

Conclusion: We suggest a perforation finding on the CT scan, a severe pain score at least above 7 on a numeric rating pain scale, and a left-sided lesion are absolute indications for in-hospital management.

Keywords: Diverticulitis; Predictive factors

\section{INTRODUCTION}

Diverticulitis is one of the major causes of an acute abdomen in emergency departments [1]. Its incidence has increased over the past decades. According to a large-scale study in the United States between 1998 and 2005, the admission rate for diverticulitis increased to $26 \%$, and elective operations for diverticulitis increased over 29\% [2, 3]. In Western countries, diverticulosis and diverticulitis mostly occur in the left side of the colon, especially in the sigmoid colon where the intraluminal pressure is higher than it is

Received: August 25, 2017 - Accepted: October 24, 2017

Correspondence to: Keun Ho Yang, M.D.

Department of Surgery, Inje University Sanggye Paik Hospital, Inje University College of Medicine, 1342 Dongil-ro, Nowon-gu, Seoul 01757, Korea

Tel: +82-2-950-1017, Fax: +82-2-933-9389

E-mail: ileus@paik.ac.kr

ORCID code: https://orcid.org/0000-0003-1039-4093

(C) 2018 The Korean Society of Coloproctology

This is an open-access article distributed under the terms of the Creative Commons Attribution NonCommercial License (http://creativecommons.org/licenses/by-nc/4.0) which permits unrestricted noncommercial use, distribution, and reproduction in any medium, provided the original work is properly cited. in other segments of the colon [4]. However, in Eastern countries, especially in Korea, diverticulitis occurs predominantly in the right side of the colon around the cecum [5].

Most people with diverticulosis remain asymptomatic, but $25 \%$ will develop an episode of symptomatic diverticular disease. Among the symptomatic diverticulitis patients, about $14.4 \%$ to $17.4 \%$ require elective surgery [3]. When patients visit the Emergency Department (ED), the priority of diverticulitis treatment has usually been based on the severity of the disease, the clinical history of abdominal pain, physical examination and laboratory findings, and abdominopelvic computed tomography (CT) findings [6]. Classically, acute diverticulitis is essentially a surgical disease that requires multistep decision-making in terms of the timing and the type of operation. Sometimes, doctors face severe septic diverticulitis with a perforation that requires surgical intervention to resolve sepsis and/or to repair or resect a perforated bowel. We, the authors, tried to determine the predictive factors affecting hospital duration and elective surgical intervention in patients with acute diverticulitis and then tried to determine the patient group most in need of in-hospital management. 


\section{METHODS}

We retrospectively collected medical data on patients who had been diagnosed with acute diverticulitis at Inje University Sanggye Paik Hospital between January and December 2016. Data from a total of 125 diverticulitis cases, including 2 cases of recurrence, involving 123 patients were collected during the study period. This study was approved by the Institutional Review Board of Inje University, Sanggye Paik Hospital. And written informed consent was not needed due to the study being retrospective. Eleven surgery cases were identified. Among them, we excluded 8 emergent surgery cases that had clinical signs of pan-peritonitis initially but then underwent surgery first. Operations were not performed in the 2 cases of recurrence. Therefore, a total of 117 cases involving 115 patients were enrolled in this study. The following clinical factors were documented: age, sex, body mass index (BMI), score on the numeric rating scale (NRS) as the pain scale, body temperature, white blood cell (WBC) count, C-reactive protein (CRP), nil per os (NPO) time, hospital duration, CT findings, location of diverticulitis, operation performed, and presence of comorbidity (e.g., hypertension and diabetes mellitus). In this study, NPO time was defined as the time from ER admission to the first sips of water during the hospital stay. Perforated diverticulitis was defined in CT findings as the presence of any amount of extraluminal free air and abscess formation described by an abdominopelvic radiology specialist.

We analyzed relevant factors affecting the duration of the hospital stay and the operation performed among various clinical factors. First, we examined the age distribution and divided patients into 2 age groups: over 60 years of age and 60 years of age or under. We also divided each of the remaining variables into 2 groups based on similar cutoff values: BMI $\left(23 \mathrm{~kg} / \mathrm{m}^{2}\right)$, pain scale (NRS $7)$, body temperature $\left(37.8^{\circ} \mathrm{C}\right), \mathrm{WBC}$ count $(15,000 / \mu \mathrm{L}), \mathrm{CRP}(10$

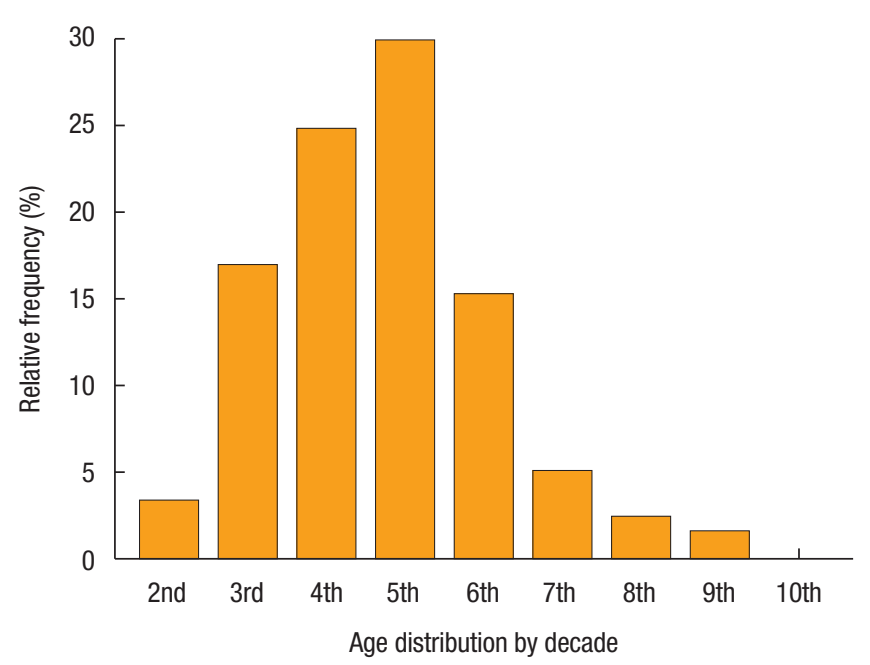

Fig. 1. Age distribution of patients with acute diverticulitis. $\mathrm{mg} / \mathrm{dL}$ ), NPO time (2 days), hospital duration (6 days), CT findings (perforation/no perforation), location of diverticulitis (right-/ left-sided colonic diverticulitis), operation performed (performed/not performed), and comorbidity (present/absent).

The data were analyzed with standard statistical software (MedCalc ver. 15.11.1, MedCalc, Ostend, Belgium). The chi-square test was used to analyze the discrete variables, and the logistic regression test was used for the multivariate analysis with the stepwise variable selection method. The results were considered statistically significant at a significance level of $5 \%$.

\section{RESULTS}

The sex breakout was 62 female (53\%) and 55 male patients (47\%). The median age was 42.0 years old ( $95 \%$ confidence interval [CI], 39.0-46.0), and the peak incidence of age was the fifth decade, followed by the fourth and the third decades (Fig. 1). The mean hospital stay and the mean NPO time were 5.5 and 3.29 days, respectively. The mean hospital stay and the mean NPO time showed an increasing tendency with increasing age distribution (Fig. 2, Table 1). The median NRS pain score was 6 (95\% CI, $5-7)$, the median body temperature was $37.5^{\circ} \mathrm{C}(95 \% \mathrm{CI}, 37.2-$ 37.6), and the median BMI was $23.6 \mathrm{~kg} / \mathrm{m}^{2}$ (95\% CI, 22.5-24.2) (Table 2). One hundred seven cases presented with right-sided colonic diverticulitis, and 10 cases with left. Operations were performed in 3 cases (2.5\%): 2 on the left and 1 on the right side of the colon (Tables 3-5).

In the univariate analysis, hospital stay was longer in the groups with older age ( $>60$ years old $)(\mathrm{P}=0.018)$, higher body temperature $\left(>37.8^{\circ} \mathrm{C}\right)(\mathrm{P}=0.047)$, higher $\mathrm{CRP}(>10 \mathrm{mg} / \mathrm{dL})(\mathrm{P}=0.025)$, perforation on the CT scan $(\mathrm{P}<0.001)$, and left-sided colonic diverticulitis $(\mathrm{P}=0.074)$ (Table 3$)$. NPO time was longer in the groups with higher NRS score $(>7)(\mathrm{P}=0.006)$, higher body tem-

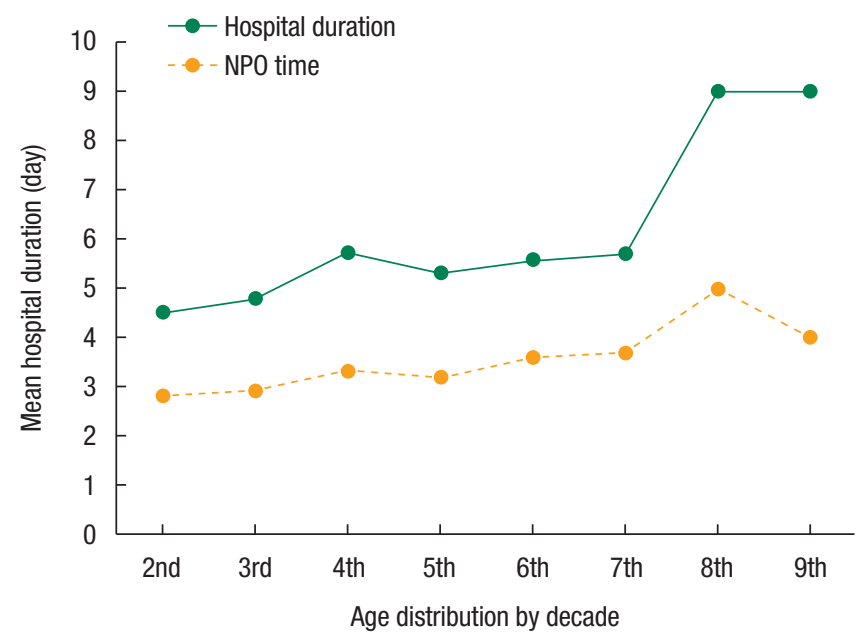

Fig. 2. Mean hospital duration and nil per os (NPO) time according to age distribution for patients with acute diverticulitis. 
Table 1. Clinical characteristics according to age distribution by decade of acute diverticulitis patients

\begin{tabular}{lcccc}
\hline \multirow{2}{*}{ Age decade (n) } & \multicolumn{2}{c}{ Sex } & Mean hospital & $\begin{array}{c}\text { Mean NP0 } \\
\text { time (day) }\end{array}$ \\
\cline { 2 - 3 } & Female & Male & duration (day) & time \\
\hline 2nd (4) & $4(100)$ & $0(0)$ & 4.5 & 2.8 \\
3rd (20) & $10(50)$ & $10(50)$ & 4.8 & 2.9 \\
4th (29) & $10(35)$ & $19(65)$ & 5.7 & 3.3 \\
5th (35) & $19(54)$ & $16(46)$ & 5.3 & 3.2 \\
6th (18) & $13(72)$ & $5(28)$ & 5.6 & 3.6 \\
7th (6) & $3(50)$ & $3(50)$ & 5.7 & 3.7 \\
8th (3) & $1(33)$ & $2(67)$ & 9.0 & 5.0 \\
9th (2) & $2(100)$ & $0(0)$ & 9.0 & 4.0 \\
117 & 62 & 55 & $5.5^{\mathrm{a}}$ & $3.29^{\mathrm{a}}$ \\
\hline
\end{tabular}

Values are presented as number (\%).

NPO, nil per os.

aMean values of total enrolled cases.

Table 2. Clinical characteristics of patients with acute diverticulitis patients in the last year

\begin{tabular}{lcc}
\hline Characteristic & Mean value $(95 \% \mathrm{Cl})$ & Median value $(95 \% \mathrm{Cl})$ \\
\hline Age $(\mathrm{yr})$ & $40.3(17.0-87.0)$ & $42.0(39.0-46.0)$ \\
Body mass index $\left(\mathrm{kg} / \mathrm{m}^{2}\right)$ & $23.34(15.2-34.8)$ & $23.61(22.6-24.2)$ \\
Pain score (NRS) & $5.3(2.0-10.0)$ & $6.0(5.0-7.0)$ \\
Body temperature $\left({ }^{\circ} \mathrm{C}\right)$ & $37.5(36.0-40.6)$ & $37.5(37.2-37.6)$ \\
\hline
\end{tabular}

$\mathrm{Cl}$, confidence interval; NRS, numeric rating scale.

perature $\left(>37.8^{\circ} \mathrm{C}\right)(\mathrm{P}=0.016)$, and perforation on the $\mathrm{CT}$ scan $(\mathrm{P}=0.044)$ (Table 4$)$. Operations were frequently performed in the groups with older age ( $>60$ years old) $(\mathrm{P}<0.001)$, higher body temperature $\left(>37.8^{\circ} \mathrm{C}\right)(\mathrm{P}=0.005)$, higher $\mathrm{WBC}$ count $(>15,000$ / $\mu \mathrm{L})(\mathrm{P}=0.010)$, presence of perforation on the CT scan $(\mathrm{P}<$ $0.0001)$, and left-sided colonic diverticulitis $(\mathrm{P}<0.001)$ (Table 5).

In the multivariate analysis, hospital stay was related with statistical significance to a perforation on the CT scan $(\mathrm{P}<0.001)$ (Table 6). Longer NPO time was related with higher NRS score $(>7)(\mathrm{P}=0.011)$ (Table 7). Operations were mainly performed on patients with left-sided colonic diverticulitis $(\mathrm{P}=0.012)$ (Table 8).

\section{DISCUSSION}

Many researchers have explored the factors related to the various clinical courses of patients with acute diverticulitis. Investigators have suggested clinical factors such as age, high body temperature, time from symptom onset to diagnosis, location of the lesion, and comorbidity could affect the clinical course of such patients [5, 7-10]. In our study, we observed that 3 factors were statistically meaningful in the clinical course of patients with acute diverticulitis: perforation findings on the CT scan, severe tender-
Table 3. Comparative univariate analysis between the 2 hospital duration groups of patients with acute diverticulitis

\begin{tabular}{|c|c|c|c|}
\hline \multirow{2}{*}{ Characteristic } & \multicolumn{2}{|c|}{ Hospital duration (day) } & \multirow{2}{*}{ P-value } \\
\hline & $\leq 6$ & $>6$ & \\
\hline Age (yr) & & & 0.018 \\
\hline$\leq 60$ & $89(84.0)$ & $17(16.0)$ & \\
\hline$>60$ & $6(54.5)$ & $5(45.5)$ & \\
\hline Sex & & & 0.269 \\
\hline Female & $48(77.4)$ & $14(22.6)$ & \\
\hline Male & 47 (85.5) & $8(14.5)$ & \\
\hline Body mass index $\left(\mathrm{kg} / \mathrm{m}^{2}\right)$ & & & 0.527 \\
\hline$\leq 23$ & $46(83.6)$ & $9(16.4)$ & \\
\hline$>23$ & $49(79.0)$ & $13(21.0)$ & \\
\hline Pain score & & & 0.916 \\
\hline$\leq 7$ & $53(81.5)$ & $12(18.5)$ & \\
\hline$>7$ & $42(80.8)$ & 10 (19.2) & \\
\hline Body temperature $\left({ }^{\circ} \mathrm{C}\right)$ & & & 0.047 \\
\hline$\leq 37.8$ & $72(85.7)$ & $12(14.3)$ & \\
\hline$>37.8$ & $23(69.7)$ & 10 (30.3) & \\
\hline 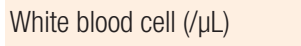 & & & 0.591 \\
\hline$\leq 15,000$ & $82(82.0)$ & $18(18.0)$ & \\
\hline$>15,000$ & $13(76.5)$ & $4(23.5)$ & \\
\hline C-reactive protein (mg/dL) & & & 0.025 \\
\hline$\leq 10$ & $86(84.3)$ & $16(15.7)$ & \\
\hline$>10$ & $9(60.0)$ & $6(40.0)$ & \\
\hline CT findings & & & $<0.001$ \\
\hline No perforation & $83(87.4)$ & $12(12.6)$ & \\
\hline Perforation & $7(41.2)$ & $10(58.8)$ & \\
\hline Location & & & 0.074 \\
\hline Right-sided & 89 (83.2) & $18(16.8)$ & \\
\hline Left-sided & $6(60.6)$ & $4(40.0)$ & \\
\hline Hypertension & & & 0.497 \\
\hline No & $83(82.2)$ & 18 (17.8) & \\
\hline Yes & $12(75.0)$ & $4(25.0)$ & \\
\hline Diabetes mellitus & & & 0.944 \\
\hline No & 91 (81.2) & $21(18.8)$ & \\
\hline Yes & $4(80.8)$ & $1(20.0)$ & \\
\hline
\end{tabular}

Values are presented as number (\%). Percentage (\%) represents \% of row total in chi-square test.

CT, computed tomography.

ness on physical examination, and left-sided lesions. These 3 factors were found to be related to a longer hospital stay for those patients.

Perforated diverticulitis has a higher possibility to become com- 
Table 4. Comparative univariate analysis between the 2 NPO period groups

\begin{tabular}{|c|c|c|c|}
\hline \multirow{2}{*}{ Characteristic } & \multicolumn{2}{|c|}{ NPO period (day) } & \multirow{2}{*}{ P-value } \\
\hline & $\leq 2$ & $>2$ & \\
\hline Age (yr) & & & 0.501 \\
\hline$\leq 60$ & $18(17.0)$ & $88(83.0)$ & \\
\hline$>60$ & $1(9.1)$ & $10(90.9)$ & \\
\hline Sex & & & 0.334 \\
\hline Female & $12(19.4)$ & $50(80.6)$ & \\
\hline Male & $7(12.7)$ & $48(87.3)$ & \\
\hline Body mass index $\left(\mathrm{kg} / \mathrm{m}^{2}\right)$ & & & 0.125 \\
\hline$\leq 23$ & $12(21.8)$ & 43 (78.2) & \\
\hline$>23$ & $7(11.3)$ & $55(88.7)$ & \\
\hline Pain score & & & 0.006 \\
\hline$\leq 7$ & $16(24.6)$ & 49 (75.4) & \\
\hline$>7$ & $3(5.8)$ & 49 (94.2) & \\
\hline Body temperature $\left({ }^{\circ} \mathrm{C}\right)$ & & & 0.016 \\
\hline$\leq 37.8$ & $18(21.4))$ & 66 (78.6) & \\
\hline$>37.8$ & $1(3.0)$ & $32(97.0)$ & \\
\hline 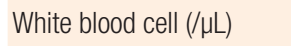 & & & 0.212 \\
\hline$\leq 15,000$ & $18(18.0)$ & $82(82.0)$ & \\
\hline$>15,000$ & $1(5.9)$ & $16(94.1)$ & \\
\hline C-reactive protein $(\mathrm{mg} / \mathrm{dL})$ & & & 0.284 \\
\hline$\leq 10$ & $18(17.6)$ & $84(82.4)$ & \\
\hline$>10$ & $1(6.7)$ & $14(93.3)$ & \\
\hline CT findings & & & 0.044 \\
\hline No perforation & $19(20.0)$ & $76(80.0)$ & \\
\hline Perforation & $0(0)$ & $17(100.0)$ & \\
\hline Location & & & 0.578 \\
\hline Right-sided & $18(16.8)$ & 89 (83.2) & \\
\hline Left-sided & $1(10.0)$ & $9(90.0)$ & \\
\hline Hypertension & & & 0.246 \\
\hline No & $18(17.8)$ & $83(82.2)$ & \\
\hline Yes & $1(6.2)$ & 15 (93.7) & \\
\hline Diabetes mellitus & & & 0.316 \\
\hline No & $19(17.0)$ & $93(83.0)$ & \\
\hline Yes & $0(0)$ & $5(100)$ & \\
\hline
\end{tabular}

Values are presented as number (\%). Percentage (\%) represent \% of row total in chi-square test.

NPO, nil per os.

plicated diverticulitis, and complicated diverticulitis accompanied by peritonitis with perforation, intra-abdominal abscess, and fistula formation is well known to require longer hospitalization [1113]. Our study showed a result similar to that of previous studies: that is, a perforation finding on the CT scan was a statistically sig-
Table 5. Comparative univariate analysis between the surgery and the nonsurgery groups

\begin{tabular}{|c|c|c|c|}
\hline Characteristic & No surgery & Surgery & P-value \\
\hline Age (yr) & & & $<0.001$ \\
\hline$\leq 60$ & $105(99.1)$ & $1(0.9)$ & \\
\hline$>60$ & $9(81.8)$ & 2 (18.2) & \\
\hline Sex & & & 0.632 \\
\hline Female & $60(96.8)$ & $2(3.2)$ & \\
\hline Male & $54(98.2)$ & $1(1.8)$ & \\
\hline Body mass index $\left(\mathrm{kg} / \mathrm{m}^{2}\right)$ & & & 0.491 \\
\hline$\leq 23$ & $53(96.4)$ & $2(3.6)$ & \\
\hline$>23$ & $61(98.4)$ & $1(1.6)$ & \\
\hline Pain score & & & 0.435 \\
\hline$\leq 7$ & $64(98.5)$ & $1(1.5)$ & \\
\hline$>7$ & $50(96.2)$ & $2(3.8)$ & \\
\hline Body temperature $\left({ }^{\circ} \mathrm{C}\right)$ & & & 0.005 \\
\hline$\leq 37.8$ & $84(100)$ & $0(0)$ & \\
\hline$>37.8$ & $30(90.9)$ & $3(9.1)$ & \\
\hline 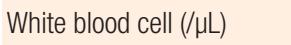 & & & 0.01 \\
\hline$\leq 15,000$ & $99(99.0)$ & $1(1.0)$ & \\
\hline$>15,000$ & $15(88.2)$ & $2(11.8)$ & \\
\hline C-reactive protein (mg/dL) & & & 0.284 \\
\hline$\leq 10$ & $100(98.0)$ & $2(2.0)$ & \\
\hline$>10$ & $14(93.3)$ & $1(6.7)$ & \\
\hline CT findings & & & $<0.001$ \\
\hline No perforation & $95(100)$ & $0(0)$ & \\
\hline Perforation & $14(82.4)$ & $3(17.6)$ & \\
\hline Location & & & $<0.001$ \\
\hline Right-sided & $106(99.1)$ & $1(0.9)$ & \\
\hline Left-sided & $8(80.0)$ & $2(20.0)$ & \\
\hline Hypertension & & & 0.487 \\
\hline No & $98(97.0)$ & $3(3.0)$ & \\
\hline Yes & $16(100)$ & $0(0)$ & \\
\hline Diabetes mellitus & & & 0.712 \\
\hline No & 109 (97.3) & $3(2.7)$ & \\
\hline Yes & $5(100)$ & $0(0)$ & \\
\hline
\end{tabular}

Values are presented as number (\%). Percentage (\%) represent \% of row total in chi-square test.

Table 6. Clinical factors related with hospital duration longer than 6 days in patients with acute diverticulitis

\begin{tabular}{lccccc}
\hline Characteristic & Coefficient & $\begin{array}{c}\text { Standard } \\
\text { error }\end{array}$ & $\begin{array}{c}\text { Odds } \\
\text { ratio }\end{array}$ & $95 \% \mathrm{Cl}$ & P-value \\
\hline $\begin{array}{c}\text { CT findings } \\
\text { perforation }\end{array}$ & 2.291 & 0.582 & 9.881 & $3.160-30.892$ & $<0.001$ \\
\hline
\end{tabular}

$\mathrm{Cl}$, confidence interval; $\mathrm{CT}$, computed tomography.

${ }^{a}$ Other meaningful variables, age, fever, and C-reactive protein, in the univariate model were not selected for the multivariate logistic regression model. 
Table 7. Clinical factors related with NPO time longer than 2 days in patients with acute diverticulitis

\begin{tabular}{lccccc}
\hline Characteristic & Coefficient & $\begin{array}{c}\text { Standard } \\
\text { error }\end{array}$ & $\begin{array}{c}\text { Odds } \\
\text { ratio }\end{array}$ & $95 \% \mathrm{Cl}$ & P-value \\
\hline Pain score $>7^{\text {a }}$ & 1.695 & 0.662 & 5.449 & $1.488-19.963$ & 0.011 \\
\hline
\end{tabular}

$\mathrm{NPO}$, nil per os; $\mathrm{Cl}$, confidence interval.

aOther meaningful variables, fever and perforation on computed tomography finding, in the univariate model were not selected for the multivariate logistic regression model.

nificant factor associated with a hospital stay of longer than 6 days.

Bowel rest is also required for patients with severe symptomatic diverticulitis [11-13]. For such patients, the recommendation is that they stay in an NPO state until symptoms and clinical signs improve. During this NPO state, patients cannot be placed in the outpatient unit because they cannot be supported by parenteral nutrition. If we could separate those patients that do not require NPO from the patients with acute diverticulitis, we would follow the former as outpatients, thus saving hospital resources and reducing public medical costs. In our study, we observed that patients who had severe pain scores, at least above NRS 7, were kept in an NPO state for more than 2 days as bowel rest.

Many studies have shown that the operation rates for acute diverticulitis in Western and Eastern countries are different. A 5\%$10 \%$ elective operation rate has been reported in Eastern countries whereas a $15 \%$ rate has been reported in Western countries $[3,7,11,14]$. Researchers have explained this difference between Western and Eastern countries as being due to various reasons, such as disease pathophysiology, age distribution of incidence, location of the disease, ethnicity, and dietary habits. The characteristics of diverticulitis in Western countries are dominance in the left-sided colon and peak incidence at old age [7, 10, 15]. In our study, we observed that the majority of the patients were less than 60 years old and that the disease occurred dominantly in the right-sided colon. Left-sided colonic diverticulitis frequently requires surgery because of the higher possibility of complications $[10,16]$. Although only 3 operations were included in our study, left-sided colonic diverticulitis was a statistically significant factor predicting the performance of an operation, which is similar to the results of other previous studies. Moreover, in this study, age, higher body temperature, and higher CRP level were meaningful factors in the univariate analysis. We observed the tendency to have a longer hospital stay in older patients; furthermore, higher body temperature was related to hospital stay, NPO time, and necessity for an operation. However, these factors were not prognostic factors in the multivariate analysis [17].

Recently, many studies have introduced outpatient management for patients with noncomplicated diverticulitis in order to minimize the hospital stay [18-20]. Thus, establishing guidelines for distinguishing between patients requiring hospitalization and
Table 8. Clinical factors related with surgery in patients with acute diverticulitis

\begin{tabular}{lccccc}
\hline Characteristic & Coefficient & $\begin{array}{c}\text { Standard } \\
\text { error }\end{array}$ & $\begin{array}{c}\text { Odds } \\
\text { ratio }\end{array}$ & 95\% Cl & P-value \\
\hline Location left-sided $^{\mathrm{a}}$ & 3.229 & 1.279 & 25.250 & $2.060-309.496$ & 0.012 \\
\hline
\end{tabular}

$\mathrm{Cl}$, confidence interval.

a Other meaningful variables, age, fever, white blood cell, and perforation on computed tomography finding, in the univariate model were not selected for the multivariate logistic regression model.

those that can be treated on an outpatient basis is important for treatment planning. Our study can support more details for identifying patients in our community with diverticulitis who would require a longer hospital stay.

Our study had some limitations. First, all data were collected retrospectively, so some clinical variables, such as scores on the NRS pain scale, signs of peritonitis, and associated gastrointestinal symptoms at the initial evaluation, were not documented on medical records well enough to minimize the clinical bias between cases. Second, the incidence of surgery was very low in this study, so we were unable to clarify the risk factors related to surgery in the patients with acute diverticulitis. In the future, prospective large-scale studies should be conducted to support our results.

In conclusion, we suggest that a perforation finding on the CT scan, a severe NRS pain score of at least above 7, or a left-sided lesion are absolute indications for in-hospital management. Furthermore, age, higher body temperature and CRP level should be considered as relative risk factors when a physician decides whether a patient should be hospitalized or not. When a physician initially encounters a diverticulitis patient in the emergency room or an outpatient facility, he/she should consider admitting that patient because of the expectation that a long hospital stay will be required. Based on our results, we are planning to verify the outpatient management criteria for patients with acute colonic diverticulitis by using a simple scoring system and to conduct a study on the safety and efficacy of outpatient management for patients with acute diverticulitis.

\section{CONFLICT OF INTEREST}

No potential conflict of interest relevant to this article was reported.

\section{REFERENCES}

1. Lopez DE, Brown CV. Diverticulitis: the most common colon emergency for the acute care surgeon. Scand J Surg 2010;99:86-9.

2. Jamal Talabani A, Lydersen S, Endreseth BH, Edna TH. Major increase in admission- and incidence rates of acute colonic diverticulitis. Int J Colorectal Dis 2014;29:937-45. 
3. Etzioni DA, Mack TM, Beart RW Jr, Kaiser AM. Diverticulitis in the United States: 1998-2005: changing patterns of disease and treatment. Ann Surg 2009;249:210-7.

4. Andersen JC, Bundgaard L, Elbrønd H, Laurberg S, Walker LR, Støvring J; Danish Surgical Society. Danish national guidelines for treatment of diverticular disease. Dan Med J 2012;59:C4453.

5. Kim SY, Oh TH, Seo JY, Jeon TJ, Seo DD, Shin WC, et al. The clinical factors for predicting severe diverticulitis in Korea: a comparison with Western countries. Gut Liver 2012;6:78-85.

6. Bugiantella W, Rondelli F, Longaroni M, Mariani E, Sanguinetti A, Avenia N. Left colon acute diverticulitis: an update on diagnosis, treatment and prevention. Int J Surg 2015;13:157-64.

7. Manabe N, Haruma K, Nakajima A, Yamada M, Maruyama Y, Gushimiyagi $\mathrm{M}$, et al. Characteristics of colonic diverticulitis and factors associated with complications: A japanese multicenter, retrospective, cross-sectional study. Dis Colon Rectum 2015;58: 1174-81.

8. Reisman Y, Ziv Y, Kravrovitc D, Negri M, Wolloch Y, Halevy A. Diverticulitis: the effect of age and location on the course of disease. Int J Colorectal Dis 1999;14:250-4.

9. Kim JH, Cheon JH, Park S, Kim BC, Lee SK, Kim TI, et al. Relationship between disease location and age, obesity, and complications in Korean patients with acute diverticulitis: a comparison of clinical patterns with those of Western populations. Hepatogastroenterology 2008;55:983-6.

10. Chung BH, Ha GW, Lee MR, Kim JH. Management of colonic diverticulitis tailored to location and severity: comparison of the right and the left colon. Ann Coloproctol 2016;32:228-33.

11. Titos-García A, Aranda-Narváez JM, Romacho-López L, GonzálezSánchez AJ, Cabrera-Serna I, Santoyo-Santoyo J. Nonoperative management of perforated acute diverticulitis with extraluminal air: results and risk factors of failure. Int J Colorectal Dis 2017;32: 1503-7.

12. Sallinen VJ, Mentula PJ, Leppäniemi AK. Nonoperative management of perforated diverticulitis with extraluminal air is safe and effective in selected patients. Dis Colon Rectum 2014;57:875-81.

13. Kim BC. Nonoperative management of acute complicated diverticulitis. Ann Coloproctol 2014;30:206.

14. Song ME, Jung SA, Shim KN, Song EM, Kwon KJ, Kim HI, et al. Clinical characteristics and treatment outcome of colonic diverticulitis in young patients. Korean J Gastroenterol 2013;61:75-81.

15. Oh HK, Han EC, Ha HK, Choe EK, Moon SH, Ryoo SB, et al. Surgical management of colonic diverticular disease: discrepancy between right- and left-sided diseases. World J Gastroenterol 2014;20:10115-20.

16. Kim SH, Byun CG, Cha JW, Choi SH, Kho YT, Seo DY. Comparative study of the clinical features and treatment for right and left colonic diverticulitis. J Korean Soc Coloproctol 2010;26:407-12.

17. Mäkelä JT, Klintrup K, Rautio T. The role of low CRP values in the prediction of the development of acute diverticulitis. Int J Colorectal Dis 2016;31:23-7.

18. Moya P, Bellon M, Arroyo A, Galindo I, Candela F, Lacueva J, et al. Outpatient treatment in uncomplicated acute diverticulitis: 5-year experience. Turk J Gastroenterol 2016;27:330-5.

19. Sánchez-Velázquez P, Grande L, Pera M. Outpatient treatment of uncomplicated diverticulitis: a systematic review. Eur J Gastroenterol Hepatol 2016;28:622-7.

20. Jackson JD, Hammond T. Systematic review: outpatient management of acute uncomplicated diverticulitis. Int J Colorectal Dis 2014;29:775-81. 